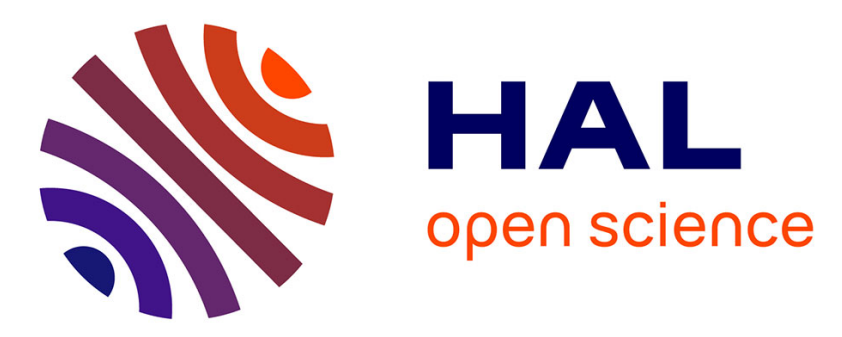

\title{
A novel experimental method for investigating secondary wetting
}

Olivier Dezellus, Bruno Jacques, Jacques Lacaze, Camille Noûs

\section{To cite this version:}

Olivier Dezellus, Bruno Jacques, Jacques Lacaze, Camille Noûs. A novel experimental method for investigating secondary wetting. Canadian Metallurgical Quarterly, 2021, pp.1-5. 10.1080/00084433.2021.1933841 . hal-03277258

\section{HAL Id: hal-03277258 \\ https://hal.science/hal-03277258}

Submitted on 2 Jul 2021

HAL is a multi-disciplinary open access archive for the deposit and dissemination of scientific research documents, whether they are published or not. The documents may come from teaching and research institutions in France or abroad, or from public or private research centers.
L'archive ouverte pluridisciplinaire HAL, est destinée au dépôt et à la diffusion de documents scientifiques de niveau recherche, publiés ou non, émanant des établissements d'enseignement et de recherche français ou étrangers, des laboratoires publics ou privés. 
Olivier Dezellus ${ }^{1}$, Bruno Jacques ${ }^{2}$, Jacques Lacaze ${ }^{2}$, Camille Noûs ${ }^{3}$

1 - LMI-UMR CNRS 5615 Université Lyon 1, France

2 - CIRIMAT, Université de Toulouse, France

3 - Laboratoire Cogitamus, France

Corresponding author: Jacques Lacaze,

CIRIMAT, ENSIACET, Université de Toulouse, 4 allée Monso, BP 44362, 31030 Toulouse, France

e-mail: Jacques.lacaze@ensiacet.fr

\section{Abstract:}

This paper proposes a novel and simple technique to study secondary wetting for bimetallic systems characterized by almost perfect primary wetting. The main principle is to promote complete dissociation between primary and secondary wettings, avoiding use of the conventional sessile drop technique and its variants. For the first time, evidence is thus obtained that secondary wetting occurs in aluminium alloys.

Keywords: wetting, secondary wetting, aluminium alloys

Word count: 2744 


\section{Introduction}

High-temperature wetting experiments in metal-metal systems are usually carried out by measuring the height, contact angle and base radius of a liquid drop deposited on a solid surface and viewed from the side. In the absence of any oxides at interfaces, metal-metal systems are characterized by low equilibrium contact angles (typically lower than $40^{\circ}$ ) and a fast spreading rate that is mainly controlled by inertial forces except when very low contact angles values are reached. In his seminal paper on wetting, de Gennes [1] cited an expression of the triple line velocity $\mathrm{U}$ derived by Joanny [2] in the case of a non-reactive system controlled by inertial forces that is given as:

$$
U=\sqrt{\frac{\sigma_{L V}}{\rho \cdot r_{d}}} \quad \text { Equation } 1
$$

where $\sigma_{\mathrm{LV}}$ is the surface tension between the liquid and the surrounding atmosphere, $\rho$ the liquid density and $r_{d}$ the radius of the drop. For a millimetre-sized droplet of liquid metal of density $4 \cdot 10^{3} \mathrm{~kg} \cdot \mathrm{m}^{-3}$, and with $\sigma_{\mathrm{LV}}$ set to $0.2 \mathrm{~J} \cdot \mathrm{m}^{-2}$, the typical velocity $\mathrm{U}$ is in the order of $0.2 \mathrm{~m} . \mathrm{s}^{-1}$. After the capillary equilibrium is reached with this high spreading rate, an additional stage characterized by a much lower spreading rate can sometimes be observed. This second stage is usually considered as "secondary wetting" and could be attributed to various local phenomena that occur at the triple line and provide an additional incremental driving force with a magnitude much lower than the initial one associated with the conventional Young equation.

High-temperature secondary wetting mechanisms have not been studied in-depth in the literature, but the most widely accepted one is based on enhancement of wetting driven by the grain boundaries intersecting the surface of the substrate. To allow spreading along the grain boundaries, the thermodynamic condition to be fulfilled is that the dihedral angle $\alpha$ formed at the liquid/solid interface is lower than a critical value $\alpha^{*}$ given by the following relation [3]; see figure 1: 


$$
\sin \left(\frac{\alpha^{*}}{2}\right)=\frac{\cos \theta_{\mathrm{Y}} \cdot \sin \theta_{\mathrm{Y}}}{\theta_{\mathrm{Y}}} \quad \text { Equation 2 }
$$

where $\theta_{\mathrm{Y}}$ is the equilibrium Young contact angle of the liquid on the solid substrate.

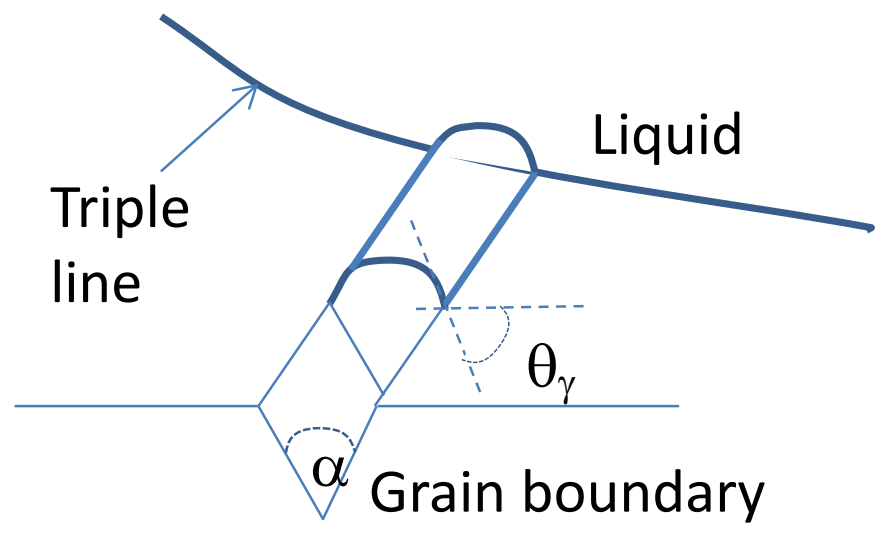

Figure 1 - Schematic diagram of secondary wetting along a grain boundary.

Typical values of dihedral angles formed at interfaces between a metallic solid substrate and a liquid metal lie between 0 and $140^{\circ}$ [4]. As a consequence, the thermodynamic condition for spreading of the liquid along the grain boundaries is fulfilled once the Young contact angle value is lower than about $20^{\circ}$. Such a condition is expected to hold for many metal/metal systems in the case of surfaces that are free of wetting barriers such as oxide films [3,5-7]. The situation is even more favourable to secondary wetting in the case of a system with two similar metals such as an Al alloy on pure Al when perfect wetting is the rule. From a kinetics point of view, secondary wetting driven by grain boundaries is controlled by grooving of the boundaries, i.e. by a dissolution-transport-growth mechanism; it is therefore expected to be much slower than primary wetting as mentioned above.

Despite the fact that secondary wetting is expected for many metal/metal systems, it is rarely reported from experimental studies. As an example, Bondi reported only two systems with secondary spreading in his review of 78 metallic systems [8], and very few more recent studies [911] mention it. In practice, however, scratches remaining on the substrate surface (e.g. from 
polishing) can be considered as capillary tubes in which the molten metal can progress, driven by capillary pressure in the same way as along grain boundaries. Wang and Conrad reported observations of this phenomenon in the case of $\mathrm{Sn}-\mathrm{Pb}$ alloys on Cu substrate [12] and calculations of its effect have been performed by Raphael in the case of a vertical plate with a groove made by controlled scratching [13]. The enhancing effect of scratches on wetting has been experimentally demonstrated by Sekulic [14] in the case of aluminium alloys.

The liquid at the nominal triple line is in contact both with the free surface of the grains, with an equilibrium contact angle that is $\theta_{Y}$, and the liquid that has filled the grain boundaries or scratches with a zero contact angle (a liquid perfectly wets a liquid of the same nature). According to the Cassie equation, the macroscopic contact angle is a weighted mean of these two values and will tend towards zero with coalescence of liquid channels ahead of the triple line. The nominal triple line is thus driven by the coalescence of the secondary wetting film, and secondary wetting therefore enhances primary wetting. Consequently, to make a clear distinction between primary and secondary wettings, it would be ideal to record both the drop profile (view from the side) and the wetted area (view from above) concomitantly. However, this is not a common practice in high-temperature capillary experiments, and it would not be easy for a number of reasons: for example, the two spreading kinetics are quite different, and contact angles, height and drop base radius are difficult to measure precisely for contact angle values lower than $20^{\circ}$.

This paper proposes a novel and simple technique to study secondary wetting for bimetallic systems characterized by almost perfect wetting. The main principle is to promote complete dissociation between primary and secondary wettings, avoiding use of the conventional sessile drop technique and its variants. The liquid phase is to appear as a film on the upper surface of a substrate while the surface of interest is the upper surface of a small piece located on the coated substrate; see the schematic diagram in figure 2-a. The liquid phase is obtained from a low-melting temperature 
material as compared to the substrate and piece materials. After heating of the assemblage and complete melting of the film, primary wetting leads to capillary rise along the vertical faces of the solid piece until the liquid reaches the corner with the horizontal surface where it is pinned; see figure 2-b. Under this configuration, secondary wetting can progress on the upper horizontal surface of the piece, while the nominal triple line remains pinned at the corner of the piece, allowing temporary dissociation between the two processes.

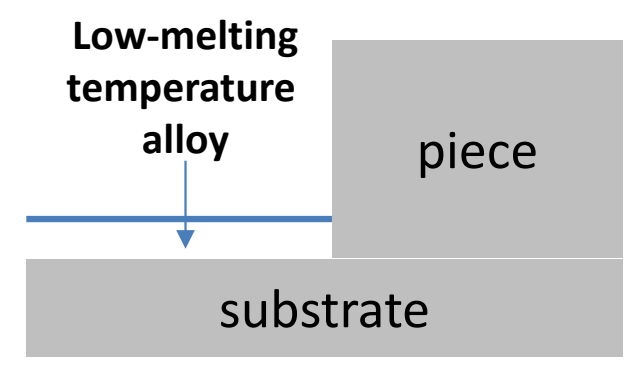

a

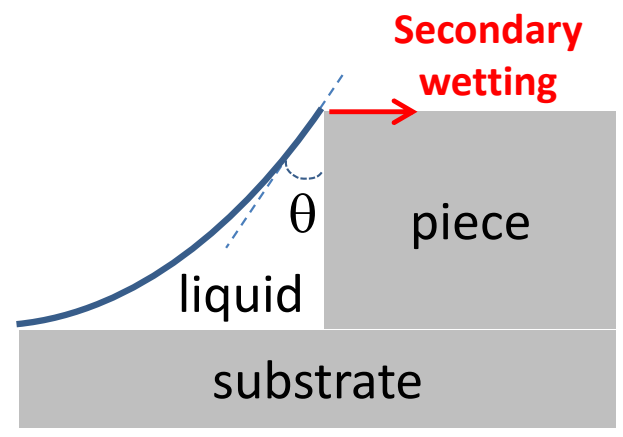

b

Figure 2. Schematic diagram of the experiment before (a) and after (b) melting of the low-melting temperature material. Note in $b$ that the liquid is pinned at the upper edge of the vertical surface of the solid piece where secondary wetting takes place.

\section{Experimental section}

Experiments were performed with a piece made of an AI-Mn alloy (AA3003) positioned on top of an AA3003 plate clad on its upper surface with $150 \mu \mathrm{m}$ of an Al-Si-Mg alloy (AA4004); see figure 3. The clad starts melting at $560^{\circ} \mathrm{C}$ and is fully liquid at $595^{\circ} \mathrm{C}$. This assemblage was positioned on a set of three BN-coated graphite heating resistors (R1-R3) whose heating power was controlled by thermocouples positioned in holes drilled within the plate. This assemblage was located inside a rig allowing for vacuum brazing. After pumping to $2 \cdot 10^{-5} \mathrm{mbar}$ for 6 hours, a heating cycle was started with an upper temperature of $605^{\circ} \mathrm{C}$ - which was reached in about 60 minutes - and held for various lengths of time before rapid cooling. The heating rate was slow enough to ensure that magnesium 
volatilization occurs when the clad starts melting at about $560^{\circ} \mathrm{C}$ [15]. The associated increase in magnesium availability destroys the native alumina layer at the outer surface of the clad, thus allowing the liquid clad to move freely [16].

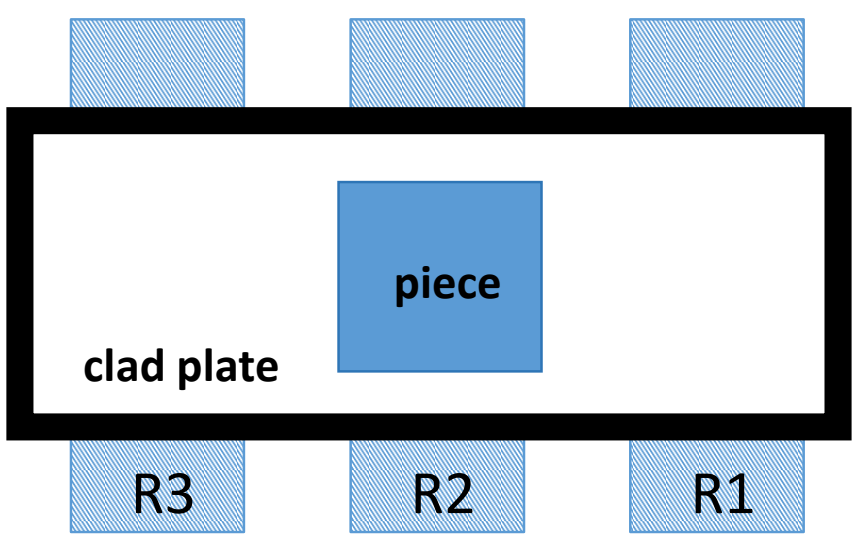

Figure 3 - Schematic diagram showing the set-up holding the clad plate on top of which a piece of AA3003 alloy was positioned. R1-R3 are BN-coated graphite heating resistors. The plate measures $1.5 \cdot 30 \cdot 80 \mathrm{~mm}^{3}$ and the piece $2 \cdot 15 \cdot 15 \mathrm{~mm}^{3}$.

The wetting process was followed with a camera through a quartz window located above the sample mounting. After the clad had melted, the formation of the joint around the piece was rapidly observed. This was immediately followed by a change in contrast on the piece upper surface that progressed from the outer edges towards the centre; see figure 4. A series of experiments was carried out after having polished the upper surface of the piece with a 1200-grit sand paper giving a roughness estimated using a SENSOSCAN to be about $10 \mu \mathrm{m}$. Using the camera records, the variations in wetting film width over time were evaluated. To do this, measurements were made from the centre of the four edges of the piece and averaged. 


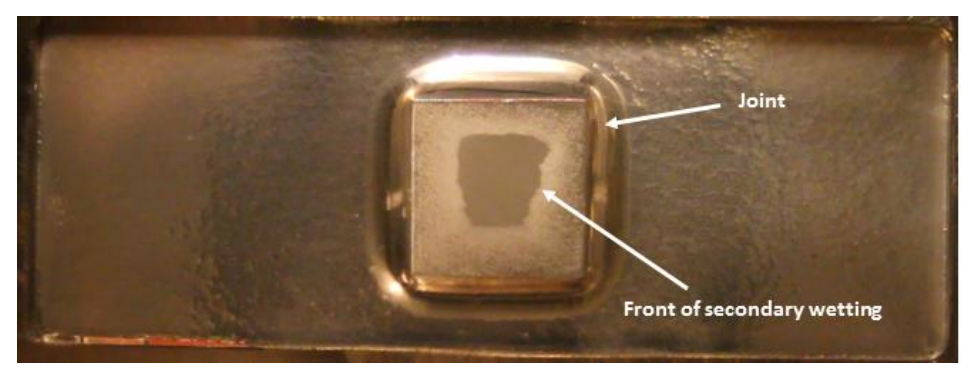

Figure 4-Snapshot of the mounting during holding at the upper temperature of the thermal cycle.

The joint around the piece and the surface covered by secondary wetting can be clearly seen due to changes in light reflection.

\section{Results}

The curves labelled 1 to 3 in figure 5 are examples where the time origin relates to the first time at which the formation of the film is detected. These curves differ in terms of the distance travelled by the wetting front during the first 10 minutes, but then show that the spreading rate stabilizes at a similar value estimated to be about $3 \cdot 10^{-7} \mathrm{~m} \cdot \mathrm{s}^{-1}$. As expected, this spreading velocity is several orders of magnitude lower than the few tenths of $m \cdot s^{-1}$ for primary wetting of a non-reactive metal-metal system [3].

As indicated above, it is expected that the spreading kinetics corresponding to secondary wetting is first controlled by wetting of scratches at the surface. Accordingly, a mirror-polished sample should show much slower wetting kinetics. This is confirmed with the curve labelled 4 in figure 5 which was obtained for a surface roughness of about $1.5 \mu \mathrm{m}$. The initial slope is seen to be more than two times smaller than those from experiments 1-3. It was also observed that secondary wetting stopped after about 6 minutes, or at least became so slow that the experiment was interrupted. 

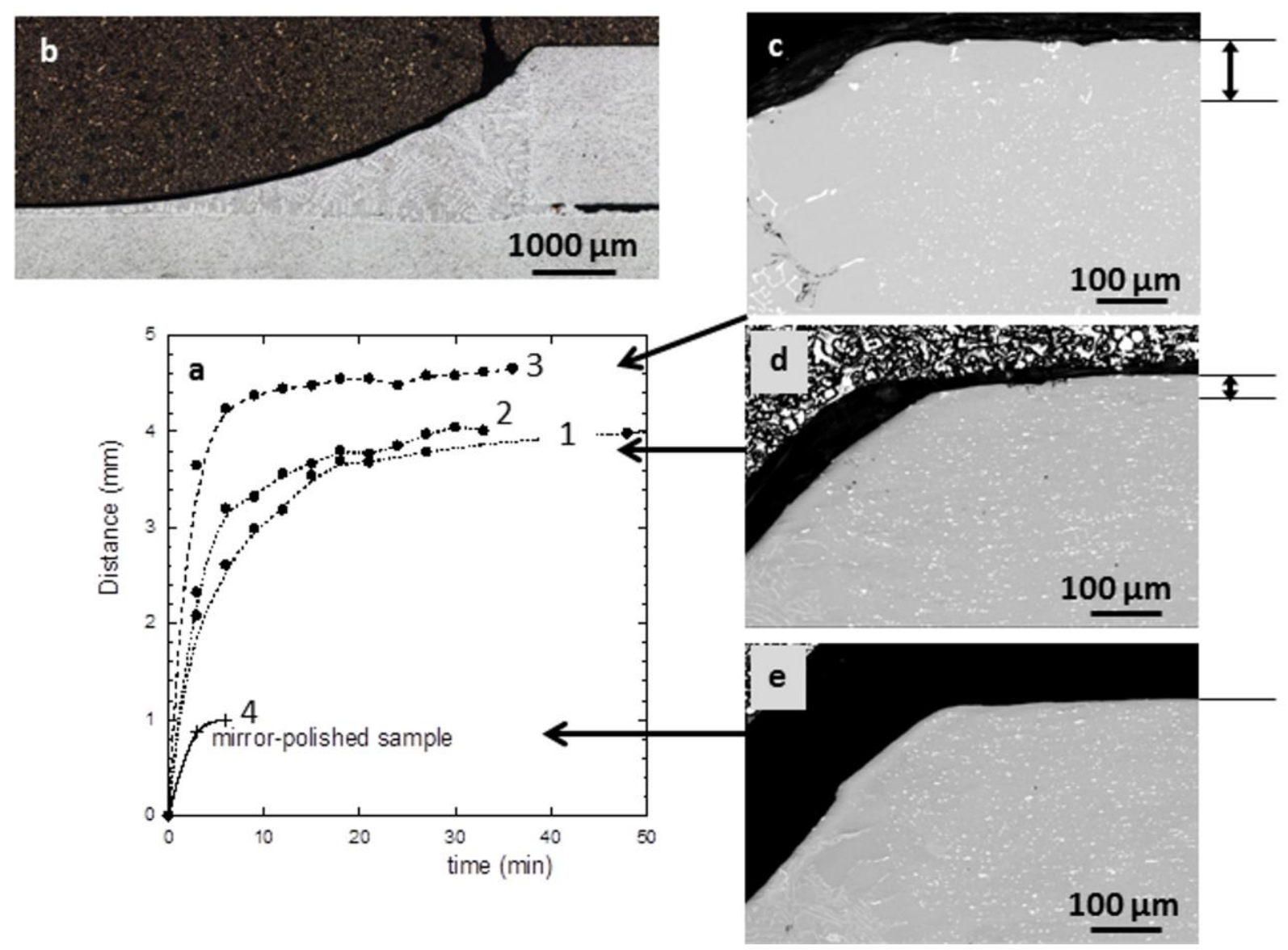

Figure 5 - Displacement of the wetting front on the 3003 piece with time (a); Optical micrograph of a section through the joint between the plate and the piece (b); Scanning electron micrographs of the vertical section through the upper part of the joint and corner of the piece (c-e) for experiments 3,1 and 4, respectively. The arrows on the right indicate the thickness of the layer deposited by isothermal solidification.

These experiments thus confirm that secondary wetting is triggered by grooves at the substrate surface, i.e., scratches left by grinding and polishing in the present case. They also suggest that the liquid film interacts with the substrate. Observation of the upper surface of sample \#4 showed the presence of a silicon-rich film in the zone which had been wetted. When examined in cross section, this film was observed to be $1-2 \mu \mathrm{m}$ thick close to the edge of the piece, becoming thinner and thinner as the travelled distance decreases. This suggests that isothermal solidification took place by diffusion of silicon from the liquid into the piece at the same time as the liquid was spreading. 
A similar enrichment in silicon could be observed at the wetted surface of samples 1-3. For these experiments, the higher liquid spreading rate was also associated with a longer spreading time. This longer time enhanced isothermal solidification and led to a much thicker solid deposit at the upper surface of the piece as compared to sample 4. The maximum thickness of this deposit at the edge of the piece was found to increase from $15 \mu \mathrm{m}$ for experiments 1 and 2 to up to $50 \mu \mathrm{m}$ for experiment 3; see the arrows on the right-hand side of Figure 4.

As expected, the thickness of the deposit decreased with the distance to the edge of the piece, i.e. with the time for interaction with the piece. This could be characterized by evidencing silicon diffusion within the AA3003 material of the piece. Silicon distribution from the surface to the bulk of the piece has been evaluated by means of energy dispersive spectroscopy (EDS) and is illustrated in figure 6 for sample 3. A first rapid mapping of the silicon distribution appears on the left of figure 6 . Then, mapping of selected areas $50 \mu \mathrm{m}$ in width and $200 \mu \mathrm{m}$ in length was carried out with a grid step of $2 \mu \mathrm{m}$. The spectra were averaged using the $8 \times 8$ neighbouring average of spot measurements and made quantitative using the phi-rho-z method. From these, profiles in four locations from the edge of the piece (position 1 in figure 6) to the triple line (position 4) were drawn as shown in the graph of figure 6. It is clearly seen that significant silicon diffusion took place within the solidified overlay and the piece below it. Furthermore, an estimate of the characteristic diffusion distance of silicon could be evaluated as $(D . t)^{0.5}$, where $D$ is the diffusion coefficient of $S i$ in the aluminium matrix and $\mathrm{t}$ is the diffusion time. For a holding of $35 \mathrm{~min}$ at $605^{\circ} \mathrm{C}$, this characteristic distance is calculated as $55 \mu \mathrm{m}$ using the diffusion coefficient assessed by Du and Chang [17]. It is seen that this value is in accordance with the silicon profiles at positions 1-3 in figure 6. 

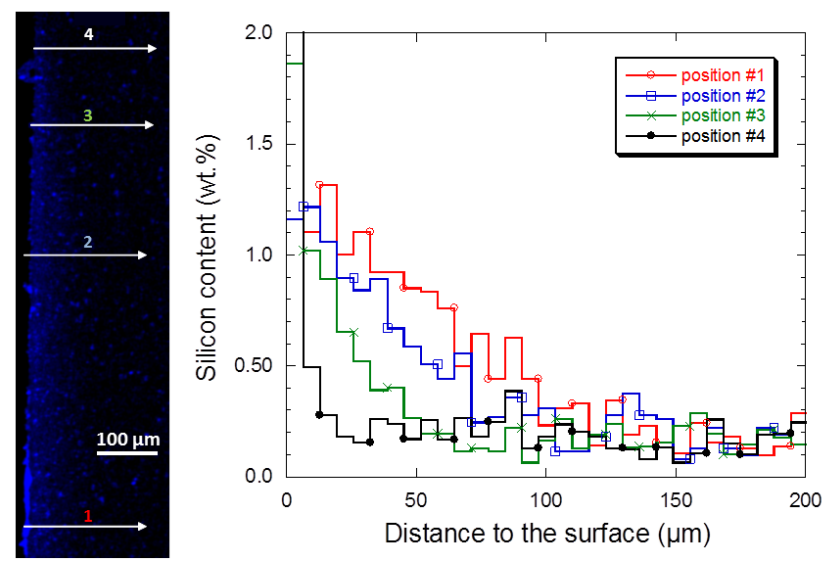

Figure 6 - EDS mapping of silicon distribution from the surface (left side of the map) towards the bulk of the piece. The related quantitative silicon profiles are plotted in the graph versus the distance to the surface from the edge of the piece (position 1) to the triple line (position 4).

After the few milliseconds required to reach macroscopic capillary equilibrium, chemical interactions start between the liquid melt and the substrate leading to local modifications in the liquid/solid interface chemistry. Dissolution of the substrate can reveal the presence of intermetallic phases and/or modify the interfacial energies, and possibly also lead to the formation of new phases. All these phenomena, which are controlled by the kinetics of chemical reactions, are therefore much slower than those inherent to primary wetting but can provide additional driving force allowing further displacement of the triple line. The resulting microstructure at the secondary wetting front is under investigation.

\section{Conclusion}

It is thus seen that capillary spreading and secondary wetting may be investigated independently from primary spreading using the proposed method, and the present results demonstrate this in the case of aluminium alloys. Figure 5 illustrates differences in the triple line velocity depending on the roughness of the surface on which secondary wetting takes place. This novel experimental technique 
can be improved and used to study other systems, allowing more precise investigation of secondary wetting when uncoupled from primary wetting.

Declaration of interest: no known conflict

Funding: no special funding was received

\section{References}

[1] De Gennes P 1985 Rev. Mod. Phys. 57827.

[2] Joanny J F 1985 PhD Thesis (Paris: University Paris 6)

[3] Eustathopoulos N, Nicholas M G and Drevet B 1999 Wettability at High Temperatures (UK: Pergamon)

[4] Eustathopoulos N 1983 Int. Met. Rev. 28189

[5] Protsenko P, Terlain A, Traskine V and Eustathopoulos N 2001 Scr. Mater. 451439

[6] Dezellus O and Eustathopoulos N 2010 J. Mater. Sci. 454256

[7] Naidich Ju V 1981 in D A Cadenhead and J F Danielli (Eds.), Progress in Surface and Membrane Science (New York: Academic Press) p 353

[8] Bondi A 1953 Chem. Rev. 52417

[9] Bailey G and Watkins H 1951 J. Inst. Met. 8057

[10] Sharps P R, Tomsia A P and Pask J A 1981 Acta Metal. 29855

[11] Weirauch D A and Krafick W J 1996 J. Mater. Res. 111897

[12] Wang X H and Conrad H 1995 Metal. Mater. Trans. A 26459

[13] Raphaël E 1989 J. Phys. France 50485

[14] Sekulic D P 2011 Heat Transfer Eng. 32648

[15] Winterbottom W L and Gilmour G A 1976 J. Vac. Sci. Technol. 13634

[16] Creber D K, Ball J and Field D J 1987 SAE Transactions 96648 
[17] Yong Du and Chang Y A 2003 Mater. Sci. Eng. A 363140

\section{Une nouvelle méthode expérimentale pour l'étude du mouillage secondaire}

\section{Résumé:}

Cet article présente une technique simple et originale pour l'étude du mouillage secondaire de systèmes bimétalliques caractérisés par un mouillage primaire presque parfait. Le principe consiste à favoriser la dissociation complète entre mouillage primaire et mouillage secondaire, en évitant I'utilisation de la technique conventionnelle de la goutte posée ou d'une de ses variantes. Pour la première fois, il est démontré que le mouillage secondaire se produit dans les alliages d'aluminium. 